\title{
Benign versus life-threatening causes of pneumatosis intestinalis: differentiating CT features
}

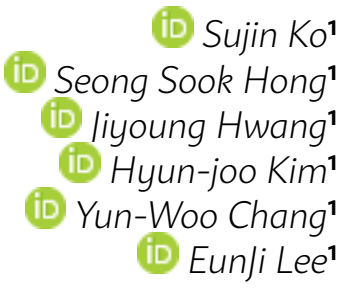

1. Department of Radiology, Soonchunhyang University Seoul Hospital, Seoul, South Korea

\section{SUMMARY}

OBJECTIVE: To assess the diagnostic performance of CT findings in differentiating causes of pneumatosis intestinalis (PI), including benign and life-threatening causes.

METHODS: All CT reports containing the word "pneumatosis" were queried from June 1st, 2006 to May 31st, 2015. A total of 42 patients with PI were enrolled (mean age, 63.4 years; 23 males and 19 females) and divided into two groups on based on electronic medical records: a benign group $(n=24)$ and a life-threatening group $(n=18)$. Two radiologists reviewed CT images and evaluated $C T$ findings including bowel distension, the pattern of bowel wall enhancement, bowel wall defect, portal venous gas (PVG), mesenteric venous gas (MVG), extraluminal free air, and ascites.

RESULTS: CT findings including bowel distension, decreased bowel wall enhancement, PVG, and ascites were more commonly identified in the life-threatening group (all p<0.05). All cases with PVG were included in the life-threatening group (8/18 patients, 44.4\%). Bowel wall defect, extraluminal free air, and mesenteric venous gas showed no statistical significance between both groups.

CONCLUSION: PI and concurrent PVG, bowel distension, decreased bowel wall enhancement, or ascites were significantly associated with life-threatening causes and unfavorable prognosis. Thus, evaluating ancillary CT features when we encountered PI would help us characterize the causes of PI and determine the appropriate treatment option.

KEYWORDS: Pneumatosis cystoides intestinalis. Pneumoperitoneum. Intestinal perforation. Mesenteric ischemia.

\section{INTRODUCTION}

Pneumatosis intestinalis (PI) is a radiographic or physical finding characterized by gas infiltration into the wall of the intestine. The clinical significance of PI can vary as it is the result of benign or life-threatening medical conditions and also can be an incidental finding ${ }^{1-3}$. Although the pathophysiology of PI remains unclear, three mechanisms have been proposed as the cause of intestinal wall gas: (1) intraluminal gas entering the bowel wall through mucosal breaks, which may cause gas spread along the mesentery ${ }^{4,5}$; (2) luminal bacteria producing excessive amounts of hydrogen gas, causing intestinal luminal pressure increase and resulting in directly-forced gas trapped within the submucosa ${ }^{6,7}$; and (3) pulmonary gas from alveolar rupture, coursing through the mediastinum to the retroperitoneum and mesentery ${ }^{8}$.

PI is traditionally considered a sign of bowel wall infarction and a surgical emergency, especially in

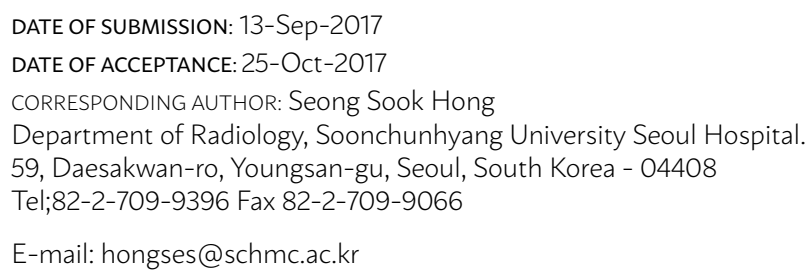


cases associated with portomesenteric venous gas ${ }^{9}$ or pneumoperitoneum ${ }^{1,2,10}$. The mortality rates of PI are reported $65 \%-86 \%$ in previous studies when accompanied by portal venous gas (PVG) ${ }^{11-14}$. However, recently numerous non-ischemic causes of PI have been described because of the improved sensitivity in detection of PI by computed tomography (CT): non-ischemic causes of PI include inflammatory bowel disease, intestinal dilatation, connective tissue disease, organ transplantation or post-operative change, immune-deficiency status, and chemotherapy ${ }^{15-19}$. PI induced by these non-ischemic causes commonly show a benign clinical course and require conservative management rather than surgery. Due to the increased incidence of PI and an increased number of causes, including both life-threatening and benign ones, it is still confusing to select the most appropriate treatment option in clinical practice. Furthermore, sometimes surgical intervention is unnecessary and even harmful. Thus, an evaluation for the specific cause of PI is clinically important to reduce unnecessary surgery, leading to improved clinical outcomes of the patients.

The purpose of this study is to assess the diagnostic performance of the CT findings in the characterization of causes of PI, including benign and life-threatening causes.

\section{METHODS}

\section{Subjects}

This study was approved by our institutional review board, which waived the need for informed consent. The CT scan database of the radiologic department was queried for all reports containing the word "pneumatosis" from June $1^{\text {st }}, 2006$ to May $31^{\text {st }}$, 2015. Among the selected reports, we secondarily looked for reports which included any of the following terms: "pneumoperitoneum", "pneumoretroperitoneum", "free air", or "extraluminal air". We then confirmed the report findings by review of CT scan images. Repeated CT scans on the same patient were excluded from the analysis. Finally, 42 consecutive patients with PI were enrolled (mean age, 63.4 years; range, 30-91 years; 23 males and 19 females). We assessed their clinical status at the time of the CT scan by reviewing their electronic medical records (EMR), including their vital signs and the presence of clinical symptoms, such as abdominal pain. The clinical course and management were also assessed based on the EMR. The enrolled patients were divided into two groups by reviewing clinical reports on EMR that were written on the same day or prior to the CT scan: The benign group, $n=24$, had no symptom complaints or minimal symptoms, including abdominal discomfort, and the possible cause of PI was considered as a benign disease entity; the life-threatening group, $\mathrm{n}=18$, presented severe abdominal pain or unstable vital signs.

\section{Image analysis}

Thirty-seven patients were examined using a 64-detector CT scanner (Sensation 64; Simens Medical System, Erlangen, Germany), the other 5 patients underwent other CT scanners (two patients, Sensation 4, Simens Medical System, Erlangen, Germany; two patients, GE Discovery CT 750HD, GE Healthcare, Waukesha, WI, USA; and one patient scanned using Light Speed VCT, GE Healthcare, Waukesha, WI, USA). Intravenous contrast media were used in most of the patients and only two of them underwent a non-enhanced scan due to poor renal function.

Two radiologists (a board-certified abdominal radiology expert with 10 years of experience and a radiology expert with 3 years of experience) reviewed all CT images independently. The readers were blinded to the clinical diagnosis of the enrolled patients and evaluated the following CT findings: pattern of bowel wall enhancement, presence of bowel distension or bowel wall defect, extraluminal free air (pneumoperitoneum or pneumoretroperitoneum), portal venous gas (PVG) or mesenteric venous gas (MVG), and the presence of ascites. The pattern of bowel wall enhancement was categorized as decreased and normal and was determined by comparison with that of the adjacent bowel wall. The MVG was determined when extraluminal gas appeared as a linear or curvilinear shape along the mesenteric border of bowel loops, especially the bowel segment showing PI (Fig.1).

\section{Statistics}

All statistical analyses were performed using SPSS for Windows version 15.0 (SPSS Inc., Chicago, IL, USA). Results were expressed as mean \pm SD unless stated otherwise. A comparison of the CT findings between both groups was performed using Fisher's exact test. A P value inferior to 0.05 was considered to be statistically significant. 

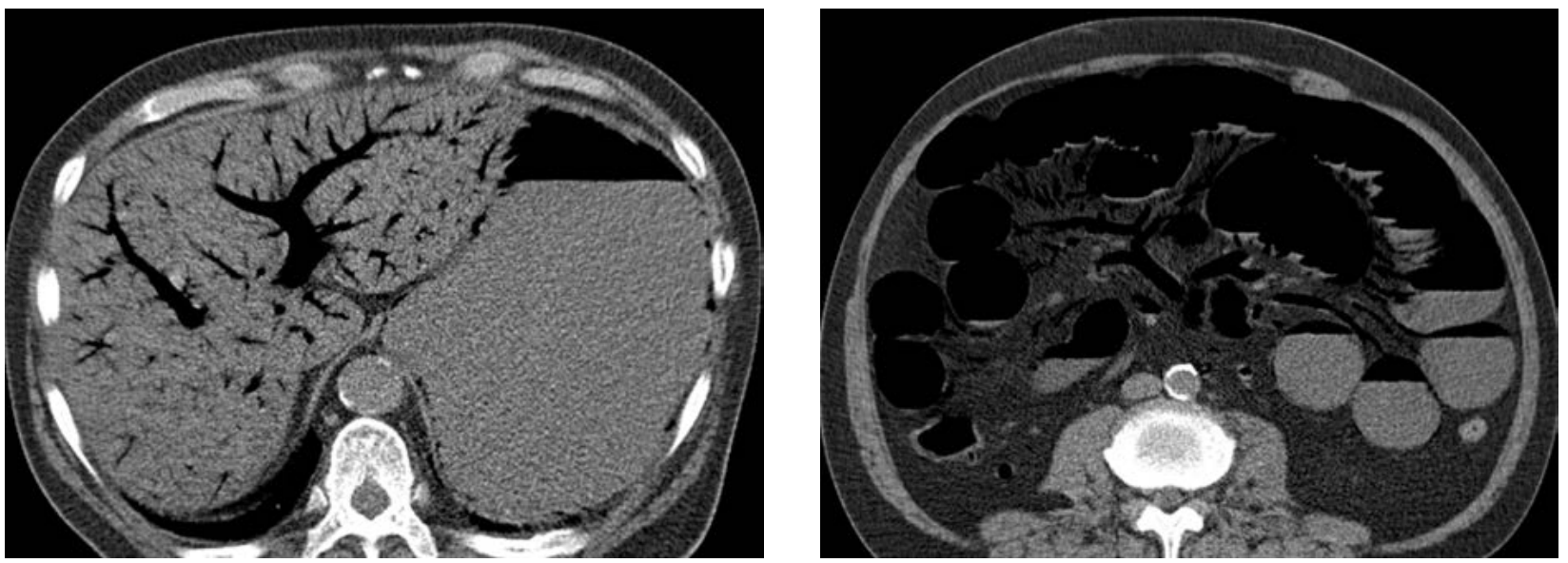

FIG. 1. A 59-YEAR-OLD MALE WHO PRESENTED ACUTE ABDOMINAL PAIN.

A. Axial precontrast CT image shows diffuse small bowel distension with PI and extensive MVG. B. Extensive PVG is also shown on precontrast CT scan. Decreased bowel wall enhancement was also identified, probably as a result of extensive bowel ischemia in this case. This patient experienced sudden cardiac arrest immediately after CT scanning and finally expired.

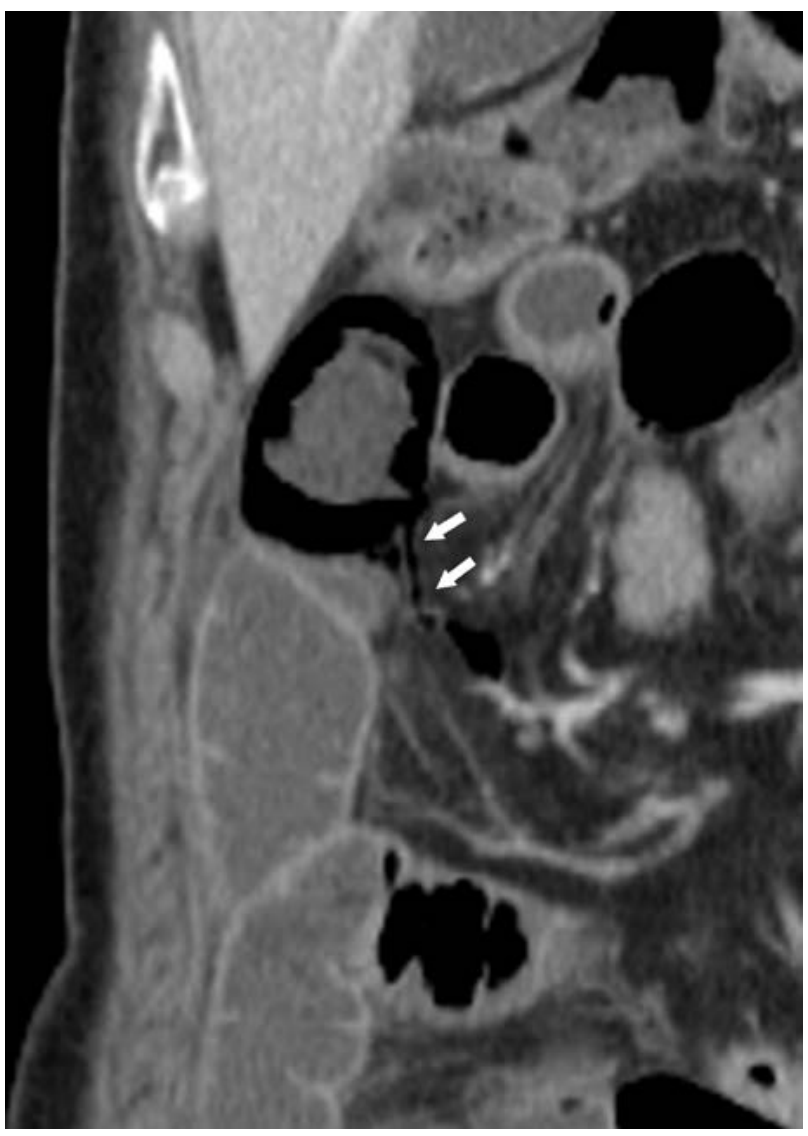

FIG.2. A 76-YEAR-OLD MALE WHO PRESENTED ABDOMINAL PAIN.

Coronal reformatted contrast-enhanced CT image shows PI in jejunal loops and an associated small amount of mesenteric venous gas (white arrow). This patient underwent conservative treatment and the abdominal pain subsided. PI was also resolved on follow up abdomen CT scan.

\section{RESULTS}

\section{CT findings}

Results of the comparison of CT measurements between both patient groups are summarized in Table 1. The CT findings including bowel distension, decreased bowel wall enhancement, PVG, and ascites were significantly more commonly identified in the life-threatening group (all $p<0.05$ ). The life-threatening group showed more frequent bowel distension and decreased bowel wall enhancement with statistical significance (bowel distension, $20.8 \%$ vs. $83.3 \%, p<0.001$; and decreased bowel wall enhancement, $4.5 \%$ vs. $77.8 \%, p<0.001)$. All cases with PVG were included in the life-threatening group (Fig.1) (8/18 patients, 44.4\%, $p<0.001)$. Ascites was more frequently detected in the life-threatening group (13/18 patients, $72.2 \%)$ than in the benign group (7/24 patients, $29.2 \%$ ) and the result was statistically significant $(p=0.012)$. No significant correlation was seen between both patient groups in the analysis of CT findings, such as bowel wall defect, extraluminal free air, and MVG (Fig.2). Of all 42 patients, 2 with bowel wall defect were identified and included in the life-threatening group without clinical significance ( $p=0.196)$. MVG was detected in both two patient groups but with no statistical significance (benign group, $8 / 24$ patients, 33.3\%; and life-threatening group, $12 / 18$ patients, $66.7 \%$; $p=0.060)$.

\section{Patient Outcome}

The benign group $(n=24)$ reported no symptom or improvement of symptoms with the resolution of the detected CT findings on follow-up abdominal radiography or CT scan. None of them had any specific 
TABLE 1. CT MEASUREMENTS AND COMPARISON IN PATIENT GROUPS

\begin{tabular}{l|l|l|l}
\multicolumn{2}{c}{} & $\begin{array}{l}\text { Benign group } \\
n=24\end{array}$ & $\begin{array}{l}\text { Life-threaten- } \\
\text { ing group } \\
n=18\end{array}$ \\
\hline Bowel distension & 5 & 15 & .000 \\
\hline Decreased bowel wall enhancement & $1^{*}$ & 14 & .000 \\
\hline Bowel wall defect & $0^{*}$ & 2 & .196 \\
\hline Extraluminal free air & 13 & 11 & .757 \\
\hline PVG & 0 & 8 & .000 \\
\hline MVG & 8 & 12 & .060 \\
\hline Ascites & 7 & 13 & .012 \\
\hline
\end{tabular}

Note- Data are the number of patients and (\%), PVG=portal venous gas, MVG=mesenteric venous gas. *The tota number of patients is 22 because two patients with nonenhanced abdomen CT scan in benign group were excluded.

TABLE 2. PATIENT OUTCOME

\begin{tabular}{|c|c|c|}
\hline \multicolumn{3}{|c|}{ Benign group } \\
\hline & \multicolumn{2}{|c|}{ Conservative treatment, $n=24$} \\
\hline \multicolumn{3}{|c|}{ Life-threatening group } \\
\hline & \multicolumn{2}{|c|}{ Death, $n=1$} \\
\hline & \multicolumn{2}{|c|}{ Indicated to surgical intervention, $\mathrm{n}=13$} \\
\hline & & Undergo emergent surgery, $n=9$ \\
\hline & & Refused to undergo surgery, $n=4$ \\
\hline & \multicolumn{2}{|c|}{ Endoscopic examination proven duodenal ulcer and clipping, $n=1$} \\
\hline & \multicolumn{2}{|c|}{ Antibiotics therapy and intensive care, $n=3$} \\
\hline
\end{tabular}

medical or surgical intervention. The life-threatening group $(\mathrm{n}=18)$ was recommended surgical intervention at the presentation due to unstable vital signs or hospitalization with close observation. Of the patients in the life-threatening group, 9 underwent emergency surgery due to bowel ischemia, 1 died immediately after taking the CT scan due to bowel ischemia, 4 were recommended for surgical intervention but refused, 3 underwent antibiotics therapy for ischemic bowel disease and were discharged with improved status, and 1 had duodenal ulcer bleeding and improved clinical status after endoscopic bleeder clipping. The patient outcome of all enrolled patients is summarized in Table 2 .

\section{Discussion}

PI is traditionally considered a surgical emergency with a high possibility of bowel ischemia, especially in cases associated with portomesenteric venous gas. However, previous studies reported that PI might occur after infection or inflammation, ulceration, surgery or trauma ${ }^{[20,21]}$. In addition, the incidence of asymptomatic PI has been increasing in association with the development of CT scanning.

In this study, PVG had statistical significance and was only identified in the life-threatening group. However, several studies ${ }^{[22,23]}$ have reported that the
PVG is not a useful indicator of bowel ischemia and is not helpful in determining the need for surgical intervention. Faberman et al. ${ }^{[22]}$ analyzed 17 patients with PMVG on CT and reported a $71 \%$ survival rate. The different result can be associated with the different study design, as they enrolled patients with PMVG and only 9 of all 17 patients had combined PI. In our study, we enrolled a larger number of patients and all of them had PI. Additionally, all of the patients with PVG were included in the life-threatening group with statistical significance. This result supports other previous larger studies ${ }^{2,24-26}$, which suggested that PI combined with PVG is associated with severe mesenteric ischemia and unfavorable clinical outcomes.

Regarding MVG, which we suspected to have similar significance when compared with PVG, it was analyzed aside of PVG. MVG was identified in about half of the patients (47.6\%) but had no statistical significance. To our knowledge, no one analyzed the incidence and significance of MVG in association with PI. The result suggests that, even though the cause of MVG is unknown, we could identify it in a relatively high incidence. Thus, we can presume MVG itself is not an ominous sign. However, when considering the statistical significance of PVG, we need further studies to analyze the association of MVG and PVG with a 
separate measurement of both CT findings.

Bowel distension and ascites were significantly more commonly identified in the life-threatening group. Concurrent bowel distension and ascites are known to be associated with high-grade obstruction and congestion. In this study, decreased bowel wall enhancement, which is a radiologic indicator of bowel ischemia, was also significantly associated with the life-threatening group. The result is similar to that of previous larger studies ${ }^{25,27}$. Duron et al. ${ }^{[27]}$ analyzed radiologic findings of 150 patients diagnosed with PI on CT and compared non-operative and operative groups; dilated bowel loops and free fluid were significantly associated with the operative group. In a study by Lee et al. ${ }^{25}$, that analyzed 123 patients with PI, decreased or absent enhancement of the bowel wall on CT were associated with increased mortality. Therefore, patients with PI and bowel distension or decreased bowel wall enhancement or ascites should be observed vigilantly.

Extraluminal free air, including both pneumoperitoneum and pneumoretroperitoneum, has been considered a sign of perforated hollow viscus and weighted heavily in favor of surgical management. However, in a previous study, it was suggested that pneumoperitoneum could occur with long-standing PI and rarely is associated with peritonitis ${ }^{28}$. In this study, extraluminal free air did not significantly correlate with patient outcome, and even the benign group presented extraluminal free air in about half of the patients (54.2\%). On the other hand, bowel wall defect on a CT scan, which is a direct indicator of perforated hollow viscus, was identified in only two patients among a total of 42 patients, with no statistical significance. In this study, two cases with both PI and bowel wall defect resulted from transmural bowel infarction: one patient had colon infarction and un- derwent emergent segmental resection of the colon; and the other expired immediately after taking the CT scan due to extensive small bowel ischemia. However, the rest of the life-threatening group showed no significant bowel wall defect, even though about twothirds of them showed extraluminal free air. This result may support that pneumoperitoneum with PI itself is not an ominous sign, so it is best to look for other critical signs such as bowel wall abnormality.

There were several limitations to the study. First, because this study was conducted at a tertiary referral center, there is a selection bias. Second, it presents a retrospective study design, so there is a possibility of insufficient clinical information. Third, about two-thirds (66.7\%) of the patients were managed nonoperatively, so it was not possible to confirm the presence or absence of bowel ischemia or other pathologic findings in both groups.

\section{CONCLUSION}

It is still difficult to determine the management of patients with PI because there are various interpretations of the clinical significance of PI and its associated CT findings.

This study revealed that the PI and concurrent PVG, bowel distension, ascites and decreased bowel wall enhancement were significantly associated with life-threatening causes of PI and unfavorable clinical outcomes. On the other hand, the presence of MVG, extraluminal free air, and bowel wall defects showed no statistical significance. Thus, it is necessary to pay attention to other ancillary CT findings when interpreting images of patients with PI to help characterize the causes of PI and determine the appropriate treatment option.

\section{RESUMO}

OBJETIVO: Avaliar o desempenho diagnóstico dos achados CT em causas diferenciadoras da pneumatose intestinal (PI), incluindo causas benignas e que ameaçam a vida.

MÉTODOS: Todos os relatórios CT contendo a palaura "pneumatose" foram questionados de 10 de junho de 2006 a 31 de maio de 2015. Um total de 42 pacientes com Pl foi matriculado (idade média 63,4 anos, 23 do sexo masculino e 19 do sexo feminino) e divididos em dois grupos na base de registros médicos elétricos: grupo benigno, $n=24$ e grupo com risco de vida, $n=18$. Dois radiologistas analisaram as imagens da CT e avaliaram seus achados, incluindo distensão intestinal, padrão de realce da parede intestinal, defeito da parede intestinal, gás venoso portal (PVG), gás venoso mesentérico (MVG), ar extraluminal e ascite.

RESULTADOS: Achados CT, incluindo distensão intestinal, diminuição do realce da parede intestinal. PVG e ascite foram mais comumente identificados em grupo com risco de vida (todos $p<0,05$, respectivamente). Todos os casos com PVG foram incluídos em grupo com risco de vida (8/18 pacientes, 44,4\%). Defeito da parede do intestino, ar livre extraluminal e gás venoso mesentérico não mostraram significância estatística entre dois grupos.

CONCLUSÃo: Pl e PVG concorrente, distensão intestinal, diminuição do aumento da parede do intestino ou ascites foram significativamente associados com causas que ameaçaram a vida e prognóstico desfavorável. Portanto, avaliar os recursos de CT auxiliares quando encontramos PI nos ajudaria a caracterizar as causas de Pl e determinar a opção de tratamento apropriada.

PALAVRAS-ChaVE: Pneumatose cistoide intestinal. Pneumoperitônio. Perfuração intestinal. Isquemia mesentérica. 


\section{REFERENCES}

1. Heng Y, Schuffler MD, Haggitt RC, Rohrmann CA. Pneumatosis intestinalis: a review. Am J Gastroenterol. 1995;90(10):1747-58.

2. Ho LM, Paulson EK, Thompson WM. Pneumatosis intestinalis in the adult: benign to life-threatening causes. AJR Am J Roentgenol. 2007;188(6):1604-13.

3. Knechtle SI, Davidoff AM, Rice RP. Pneumatosis intestinalis. Surgical management and clinical outcome. Ann Surg. 1990;212(2):160-5.

4. Galandiuk S, Fazio VW. Pneumatosis cystoides intestinalis. A review of the literature. Dis Colon Rectum. 1986;29(5):358-63.

5. Read NW, Al-Janabi MN, Cann PA. Is raised breath hydrogen related to the pathogenesis of pneumatosis coli? Gut. 1984;25(8):839-45.

6. Ellis BW. Symptomatic treatment of primary pneumatosis coli with metronidazole. Br Med J. 1980;280(6216):763-4.

7. Yale CE, Balish E, Wu JP The bacterial etiology of pneumatosis cystoides intestinalis. Arch Surg. 1974;109(1):89-94.

8. St Peter SD, Abbas MA, Kelly KA. The spectrum of pneumatosis intestinalis. Arch Surg. 2003;138(1):68-75.

9. Kernagis LY, Levine MS, Jacobs JE. Pneumatosis intestinalis in patients with ischemia: correlation of CT findings with viability of the bowel. AJR Am J Roentgenol. 2003;180(3):733-6.

10. Na SY, Kim KJ, Yang DH, Jung K, Ye B, Byeon JS, et al. Pneumoperitoneum in a patient with ulcerative colitis after sigmoidoscopy: is this always an indication for surgery? Inflamm Bowel Dis. 2011;17(6):E54-6.

11. Iannitti DA, Gregg SC, Mayo-Smith WW, Tomolonis RJ, Cioffi WG, Pricolo VE. Portal venous gas detected by computed tomography: is surgery imperative? Dig Surg. 2003;20(4):306-15.

12. Lassandro F, Scaglione M, Rossi G, Grassi R, Romano L. Portomesenteric vein gas: diagnostic and prognostic value. Emerg Radiol. 2002;9(2):96-9.

13. Liebman PR, Patten MT, Manny J, Benfield JR, Hechtman HB. Hepatic-portal venous gas in adults: etiology, pathophysiology and clinical significance. Ann Surg. 1978;187(3):281-7.

14. Paran H, Epstein T, Gutman M, Shapiro Feinberg M, Zissin R. Mesenteric and portal vein gas: computerized tomography findings and clinical significance. Dig Surg. 2003;20(2):127-32.

15. Alkhatib AA, Elkhatib FA, Alkhatib OF, Zurcher R. Pneumatosis intestinalis and gas in portal vein associated with small bowel obstruction. J Emerg Med. 2011;40(6):e125-6.
16. Hoot NR, Pfennig CL, Johnston MN, Jones I. An incidental finding? Pneumatosis intestinalis after minor trauma. J Emerg Med. 2013;44(2):e145-7.

17. Ohtsubo K, Okai T, Yamaguchi $Y$, Watanabe $H$, Motoo $Y$, Matsui $O$, et al. Pneumatosis intestinalis and hepatic portal venous gas caused by mesenteric ischemia in an aged person. J Gastroenterol. 2001;36(5):338-40.

18. Ong KP, Ng KH, Lim KH, Low SC, Eu KW. Pneumoperitoneum resulting from pneumatosis cystoides intestinalis: a rare complication of massive colonic dilatation. Tech Coloproctol. 2010;14(3):287-8.

19. Wright NJ, Wiggins T, Stubbs BM, Engledow A. Benign pneumatosis intestinalis with pneumoperitoneum and typhlitis: side-effects of drug or disease induced immunosuppression. BMJ Case Rep. 2011;13;2011.

20. Feczko PJ, Mezwa DG, Farah MC, White BD. Clinical significance of pneumatosis of the bowel wall. Radiographics. 1992;12(6):1069-78.

21. Sebastià $C$, Quiroga $S$, Espin $E$, Boyé R, Alvarez-Castells A, Armengol M. Portomesenteric vein gas: pathologic mechanisms, CT findings, and prognosis. Radiographics. 2000;20(5):1213-24.

22. Faberman RS, Mayo-Smith WW. Outcome of 17 patients with portal venous gas detected by CT. AJR Am J Roentgenol. 1997;169(6):1535-8.

23. Wiesner W, Mortelé KJ, Glickman JN, ji H, Ros PR. Pneumatosis intestinalis and portomesenteric venous gas in intestinal ischemia: correlation of CT findings with severity of ischemia and clinical outcome. AJR Am J Roentgenol. 2001;177(6):1319-23.

24. Griffiths DM, Gough $M H$. Gas in the hepatic portal veins. $\mathrm{Br} \mid$ Surg 1986;73(3):172-6.

25. Lee HS, Cho YW, Kim KJ, Lee IS, Lee SS, Yang SK. A simple score for predicting mortality in patients with pneumatosis intestinalis. Eur | Radiol. 2014;83(4):639-45.

26. Smerud MJ, Johnson CD, Stephens DH. Diagnosis of bowel infarction: a comparison of plain films and CT scans in 23 cases. AIR Am | Roentgenol. 1990;154(1):99-103.

27. Duron VP, Rutigliano S, Machan IT, Dupuy DE, Mazzaglia PI. Computed tomographic diagnosis of pneumatosis intestinalis: clinical measures predictive of the need for surgical intervention. Arch Surg. 2011;146(5):50610.

28. Koss LG. Abdominal gas cysts (pneumatosis cystoides intestinorum hominis); an analysis with a report of a case and a critical review of the literature. AMA Arch Pathol. 1952;53(6):523-49. 